Article

\title{
Survey and Classification of Business Models for the Energy Transformation
}

\author{
Johannes Giehl *(D), Hayri Göcke, Benjamin Grosse ${ }^{\mathbb{D}}$, Johannes Kochems ${ }^{\mathbb{D}}$ and \\ Joachim Müller-Kirchenbauer
}

Chair of Energy and Resource Management, Technische Universität Berlin, FH 5-3, Fraunhoferstraße 33-36, 10587 Berlin, Germany; hayri.goecke@cki.tu-berlin.de (H.G.); grosse@tu-berlin.de (B.G.);

kochems@tu-berlin.de (J.K.); mueller-kirchenbauer@er.tu-berlin.de (J.M.-K.)

* Correspondence: giehl@er.tu-berlin.de

Received: 24 April 2020; Accepted: 2 June 2020; Published: 10 June 2020

check for updates

\begin{abstract}
The energy transformation is changing the structure of the energy sector in Europe and Germany. In this paper the current structure of the energy sector is analysed both empirically as well as theoretically. Therefore, the authors have developed the business model framework for the energy transformation (BMFE). The framework is a synthesis of classical business model designs. An exhaustive survey of existing business models based on primary data collection and a literature review leads to 638 business models. Finally, 69 prototypical business models of the energy sector are the result of the classification of these business models. The information of the business models within the BMFE is applied to show the growing importance of value creation networks in energy industry. The work represents the current status of the business models in the energy sector.
\end{abstract}

Keywords: energy transformation; Energiewende; business models; business model classification; business model framework for the energy transformation; business model ontology; value creation networks

\section{Introduction}

The energy transformation process requires a consequent implementation of energy efficiency as well as a fundamental shift of energy supply towards renewable, $\mathrm{CO}_{2}$ neutral energies [1]. The process of decarbonising the energy production fosters the trend towards decentralised structures [2]. Furthermore, the digitalisation of processes and industries has an increasing impact on the energy sector and new players entering the energy markets [3,4]. The 'classical' structures of the energy industry that emerged after the liberalisation of the electricity and gas markets in Europe (see Figure 1), including established business models, are subject to massive changes [5].

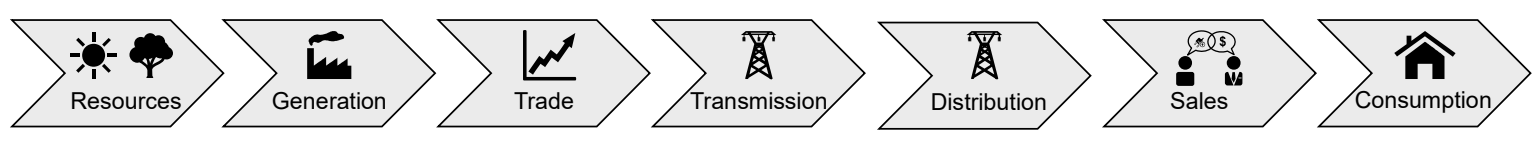

Figure 1. The classical value chain of the energy industry.

Separations and subsequent restructuring efforts of the German energy utilities E.ON and RWE illustrate the displacement trends and disruptive processes in the energy industry. In order to analyse these structural changes in the business model landscape during the energy transformation, a comprehensive empirical analysis is carried out. The analysis includes both business models and business model structures identified either in practice or in research work. This approach also covers some expected future business models.

To do so, Section 2 gives an overview of the current state of research on energy transformationrelated business models and the most common business model frameworks. Section 3 proposes 
an adjusted framework for the description of prototypical business models in the energy system transformation, followed by a brief description of the methodology used for the empirical (practical and theoretical) analysis. Section 4 presents the results of this study including a categorisation of the identified prototypical business models. An illustration of the environment around an exemplary business model elaborates further development of the classical value chain architecture into value networks. Concluding, Section 5 summarises the core results, and identifies further research questions.

The study answers three different research questions. First, business model systematisations are revised, and it is analysed to what extent they are appropriate for describing the current business models of the energy transformation. A need for further development is identified and a generic framework for the energy sector is derived. Second, the effects of the energy transition on business models and third, the effects on the value creation in the energy sector are unclear. Thus, a detailed survey of business models presents the current structure of the business model landscape and respective value chains. The result is a generic overview over existing business model in the energy sector with a focus on Europe and especially Germany. The latter is mainly by considering the national regulatory framework.

The results facilitate further analysis of existing business models and lay the basis for an individual economic quantification of business models (prototypes)(See Section 3.4 for the definition of both terms). On this basis, detailed studies of business models can be prepared and developed into business plans.

\section{Status Quo of Business Models in the Energy Sector}

The structures of the energy industry are always changing [6]. However, liberalisation and energy system transformation have significantly increased the pace of change and have impacted the business model landscape substantially. Therefore, this section presents the current business model frameworks for the systematisation of business models and current research on energy business models.

\subsection{Existing Business Model Systematisations}

The term 'business model' describes a simplified abstraction of mechanisms of business activities used to generate profits. The use of the term has increased since the 1990s [7]. Various systematisations and analysis tools for business models exist:

The term 'business model' originates in the description by Peter Drucker, who defined a good business model as a simplified abstraction of reality [8]. The term "business model" describes a simplified abstraction of corporate activities that are designed to generate profits. The use of the term has increased since the 1990s [7]. Various systematisations and analysis tools for business models exist.

The RCOV-Framework (Resources, Competences, Organisation, and Value(-Proposition)) by Demil and Lecoq (2010) analyses business models, especially from a resource-based perspective and highlights value creation from internal structures [9]. The business model Canvas by Osterwalder and Pigneur (2013) provides a snapshot of a company and is mainly used for business model innovation due to its modular structure. It covers an extensive range of both internal and external aspects of a business model through open terms [10]. The Business Model Design by David Teece (2010), on the other hand, puts greater emphasis on the underlying technology, which explains its relevance to technology-driven business models [11]. Bieger and Reinhold (2011) complement Teece by considering the company's internal value distribution and the development concept for further improving the business model within the business model analysis framework. The framework is suitable for the description of cooperative and dynamic value creation [7].

\subsection{Current Research on Energy Business Models and Resulting Research Questions}

A series of publications exist regarding the effects of energy system transformation and changing framework conditions on business models. The authors Provance et al. (2011) examine political and organisational factors influencing the business models of small electricity producers [12]. Similarly, Doleski (2014) analyses the development and change of business models [13]. PWC (2016) investigates 
the expected impact of digitisation on existing energy business models [14]. Further studies analyse the influence of technologies on the development of the energy system transformation, e.g., Varone and Ferrari (2015) [15]. The authors Burger and Luke (2017) use an empirical approach for the analysis of real business models. Based on 144 companies worldwide, they derive generic business models for photovoltaic applications, demand-side management and (thermal) energy storage [16].

The focus of Löbbe and Hackbarth (2017) lies in individual prototypical business models of energy companies in the energy system transformation process [17]. Richter (2012) analyses business model prototypes for renewable energy sources in a comparable manner. The approach is related to utilities. The result shows a concrete need to adjust the existing business models to climate aspects [18]. To the same extent, Loock (2012) develops generic business models for the use of renewable energies [19]. Strupeit and Palm (2016), on the other hand, focus specifically on strategies for business models of private and small-scale photovoltaic users [20]. Okkonen and Suhonen (2010) elaborate production-side business model types of the district heating sector [21]. The authors Jahnke et al. (2017) discuss decentralised combined heat and power applications combined with energy services [22].

The research presented by Rodríguez-Molina et al. (2014) analyses business models for smart grid applications on the prosumer level [23]. Giordano and Fulli (2011) identify business models within the smart grid value creation network [24]. Moreover, the study 'Geschäftsmodelle 2020' by EY (2016) addresses the future development and changes of classical business models without classifying them [25].

Other authors discuss business models of sector coupling. Abdelkafi et al. (2013) focus on the further development of generic business models in the context of rising e-mobility [26]. The authors Kasperk and Drauz (2013) develop basic business models for the electro-mobile value chain within the changing energy system [27].

The literature review on business models includes various studies referring to individual, specific business models, technologies, and use cases. The classical value chain is often the basis for the analysis in the aforementioned papers. Few cases give an overall view of the energy system or a systematic approach to the determination and derivation of theoretical business models.

The approach developed in this study is limited to a high-level evaluation of different business models, which aligns with other studies. This aspect concerns studies by Löbbe and Hackbarth (2017), Strupeit and Palm (2016), or Okkonen and Suhonen (2010). Burger and Luke (2017) apply a comparable approach to the empirical classification of business models of this study. However, in contrast to the approach developed here, their study is only related to a sub-sector of the energy industry.

The literature analysis shows the predominant use of existing approaches to characterise business models. These only partially consider the unique features and structural breaks of the energy system in the context of decarbonisation, decentralisation, and digitisation. This leads to the three central research gaps which are addressed by this paper. In the following parts of this work the gaps will be filled:

- Existing business model systematisations are not sufficient to characterise the business models of the energy system transformation.

- There is no exhaustive overview of currently existing energy business models.

- There is no adequate approach to describe the effects of the energy system transformation on the interactions between business models and the structure of the energy industry.

As a conclusion, our own business model framework is developed based on the existing business model frameworks and current business models. This business model framework for the energy transformation (BMFE) closes the addressed gaps. The derived overview over the business model prototypes and classes and the description of the existing energy business models in the energy system transformation process is based on the developed framework. 


\section{Methods for Identifying Business Models and Their Structure}

To fill the identified research gaps, on the one hand, the BMFE is developed (see Section 3.1), on the other, it is necessary to obtain a comprehensive picture of the current business models of the energy sector. Therefore, a primary and secondary data collection is conducted as shown in Figure 2 (see Sections 3.2 and 3.3). Further, the BMFE is used to categorise the resulting qualitative data on currently realised business models. To do so, extracted business model are grouped to prototypes and then business model classes (see Section 3.4). The following section provides information about the BMFE and its transfer to a generalised model [28].

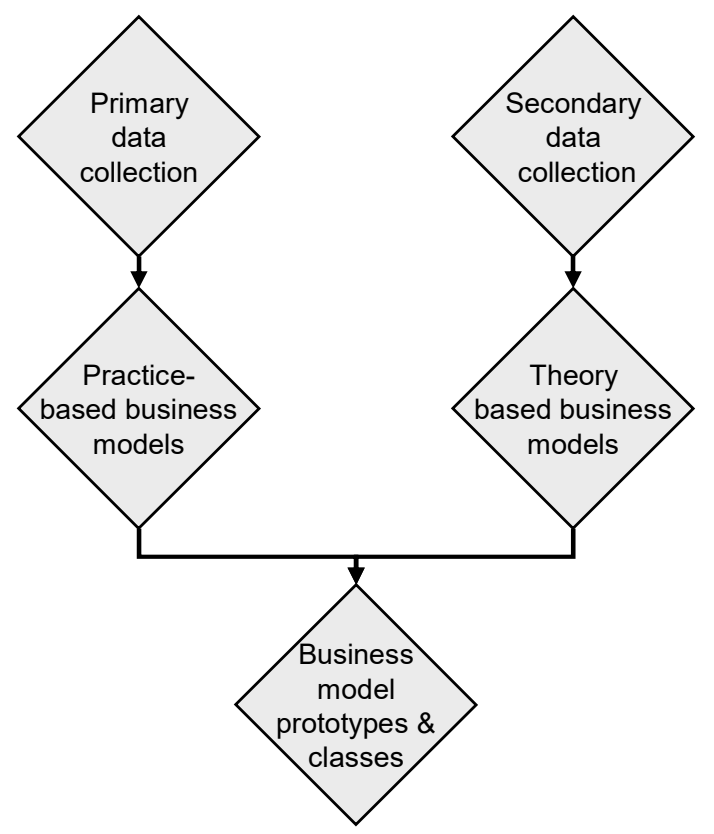

Figure 2. The procedure of business model search, typing and classification.

The analysis aims to obtain a fullest possible overview of business models without duplicates. A company with an already surveyed business model will not be further analysed. It is also assumed that a company can have several business models. As shown in Figure 3, several embedded cases (business models) can be taken from one object of investigation (company) [29].

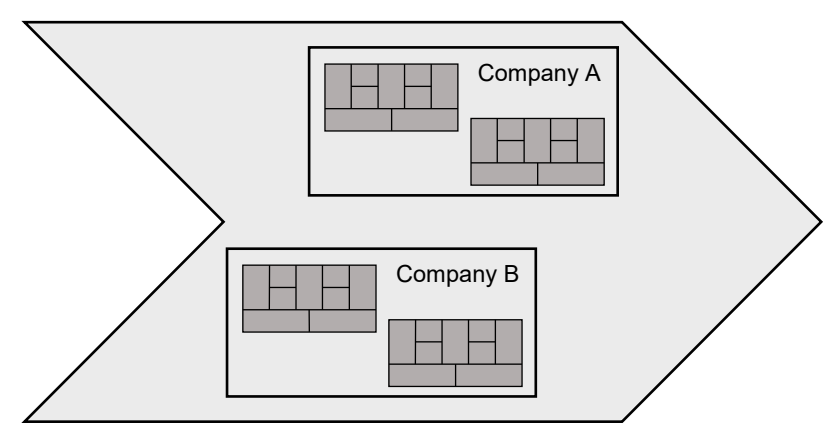

Figure 3. Business models as embedded cases in one company based on the design options for case studies by Yin (2013) [29].

The combination of theory-based and practice-based analysis, internal expert discussion, and the use of at least two independent sources ensures that the bias of the individual evaluation is minimised [30]. This procedure is particularly necessary when analysing novel business models. These are not always wholly defined and are subject to a dynamic development. 


\subsection{Development of the Business Model Framework for the Energy Transformation}

The development of the BMFE builds on the synthesis of the conducted literature analysis (see Section 2). The definition of generally valid and energy-related business model components enables the description of business models of the energy industry. The BMFE is composed of three main components. These generic descriptive components of a business model are used by other authors: [7,9-11] value proposition, customer segment and revenue model:

- The 'value preposition' describes the value a company generates for its clients.

- The 'customer segment' defines the customer groups addressed by the value preposition.

- The 'revenue model' describes how customer relationships generate cash flows into the company.

Further energy industry specific components are used. These following components sharpen the characterisation of the business models:

- The 'utilised technology' describes the central technology(s) that support the competitive advantage of the company.

- The 'required and offered data' serve within the framework to show (non-) monetarily valued data links.

- The 'influencing factors' describe energy specific technology, politics, and market aspects.

- The 'level in the values creation network' allocates the business model within the elements of the classical value chain.

- The 'function in the value creation network' is based on the business model systematics of Osterwalder and Pigneur (2013) and shows common characteristics of companies.

- The 'partners' describe the extent to which a business model depends on the existence or success of other business models.

This framework is used to characterise the business models collected in the further process. The BMFE offers the possibility to describe the structure of a concrete business model based on the characteristics of the nine BMFE components. In a further step, this systemisation facilitates the quantification of a concrete business plan.

\subsection{Procedure of the Practice-Based Analysis}

A primary data collection forms the basis for the analysis of the practically realised business models. The company data is collected via publicly accessible information. The applied case study principle corresponds with the procedure developed by Yin (2013) for cases with embedded investigation units. This allows for one investigated company realising various business models [29].

The search process has three starting points (see Figure 4) and is both theory-driven and explorative. In the theory-driven approach, German companies with the highest turnover are analysed, i.e., large utilities and public utilities, along the value chain. This approach ensures high representativeness (This approach is consistent with the approach described in [31]).

The explorative approach is oriented towards technological developments and focused on the future structure of the energy industry. Start-ups are identified using incubators. Investigated incubators are the "Global Cleantech 100", the "High-Tech Gründerfonds", and from the large German utilities.

In addition to these two approaches, associations and statements to new German energy-related laws lead to more business model information. The consideration of the association "Bundesverband der Energie- und Wasserwirtschaft (BDEW) and comments on the "German Renewable Energy Sources Act" (EEG 2017) [32], allows the investigation of further business models beyond the large companies. The components of the BMFE are used to represent the information of the business models. 


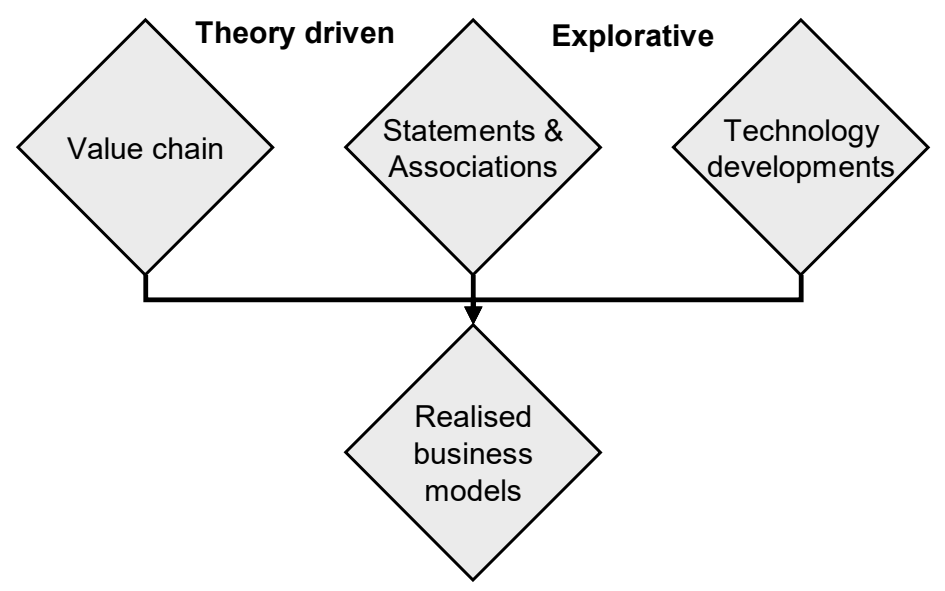

Figure 4. Approach of the practice-based analysis.

\subsection{Procedure of the Theory-Based Analysis}

The methodology for a literature review of Kitchenham and Brereton (2013) is the basis for the secondary data collection (see Figure 5) [33]. The combination of a keyword-based search and a citation-based snowballing approach results in thematically related publications. Due to the rapid changes within the energy system transformation and the importance of current trends, especially digitalisation, decarbonisation and decentralisation, the search focuses of the investigation is limited to publications since 2012 .

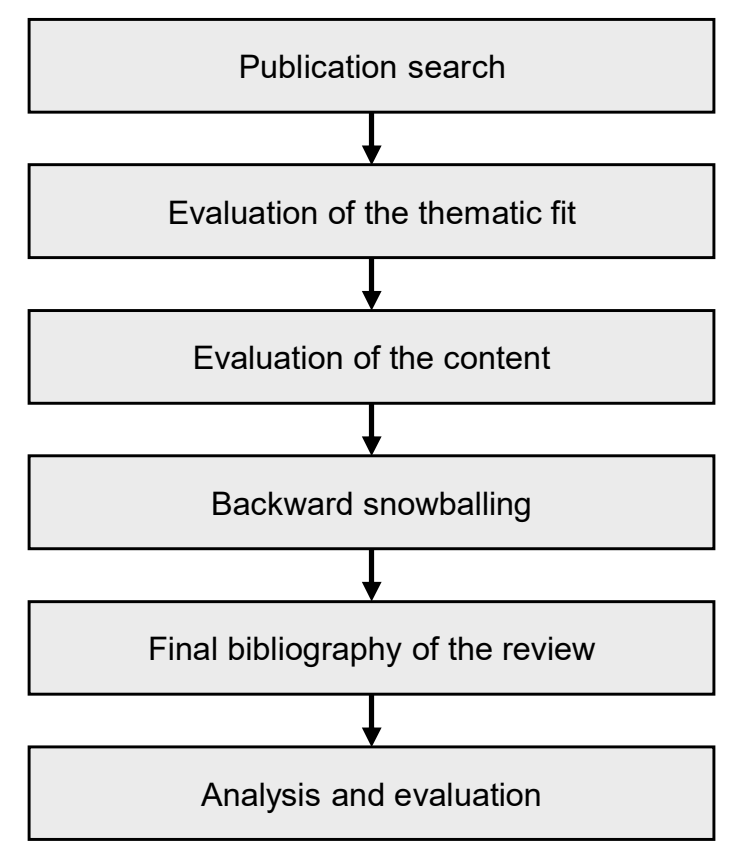

Figure 5. Procedure of the secondary data collection based on the methodology developed by Kitchenham and Brereton (2013) [33].

The search keywords correspond to the subject of the study and include the terms 'energy system transformation' and 'business models' (in German and English). Based on this, further equivalent and related terms are derived and combined to appropriate search strings using a keyword matrix. The keyword matrix can be found in Appendix A. Firstly, the collected publications are checked for business models. If the publication describes a business model, secondly, citation-based snowballing searches for further publications. Thirdly, all positively evaluated publications are analysed in detail 
and the provided information about energy-related business models transferred into the components of the BMFE.

\subsection{Synthesis to Prototypes and Classification of Business Models}

The objective of developing prototypical business models and business model classes is to group similar business models. The formed groups are as homogeneous as possible concerning their characteristics. At the same time, they are distinguishable from other prototypes or classes [34].

The analysis of the collected business models follows a two-stage filter procedure. Firstly, business model prototypes (typing) are derived. The outcomes are prototypes of the energy sector. Secondly, the business model classes (classification) are built based on the business model prototypes.

In the first step, the characteristics of the main components of the BMFE (value proposition, revenue model and customer segment) are used to characterise different prototypes as abstractions of concrete business models. In the second step, the prototypes are classified based on their position in the value creation network. The transformation of the energy industry from a carbon-intensive, capacity-oriented producing industry to a decarbonised, flexible, networked industry is emphasised.

\subsubsection{Synthesis to Business Model Prototypes}

The main components of the BMFE are the starting point for the synthesis of the prototypes. For the differentiation of the prototypes builds on the three characteristics: value proposition, revenue model and customer segment (see Figure 6, further information can be found in the supplementary material Text S1). If two business models are identical in terms of their value proposition and the revenue model and the customer structure are (almost) identical, they form one prototype. The other components of the BMFE are subsumed under the three main components. The summation is carried out in a way that ensures a clear separation. For example, if the business models use a differentiated technology, a differentiated value proposition and revenue model can also be expected. Since the three main components already have a wide range of different possible characteristics, no further components are utilised for prototyping. The further components provide a detailed description of concrete business models and are not used to generate prototypes.

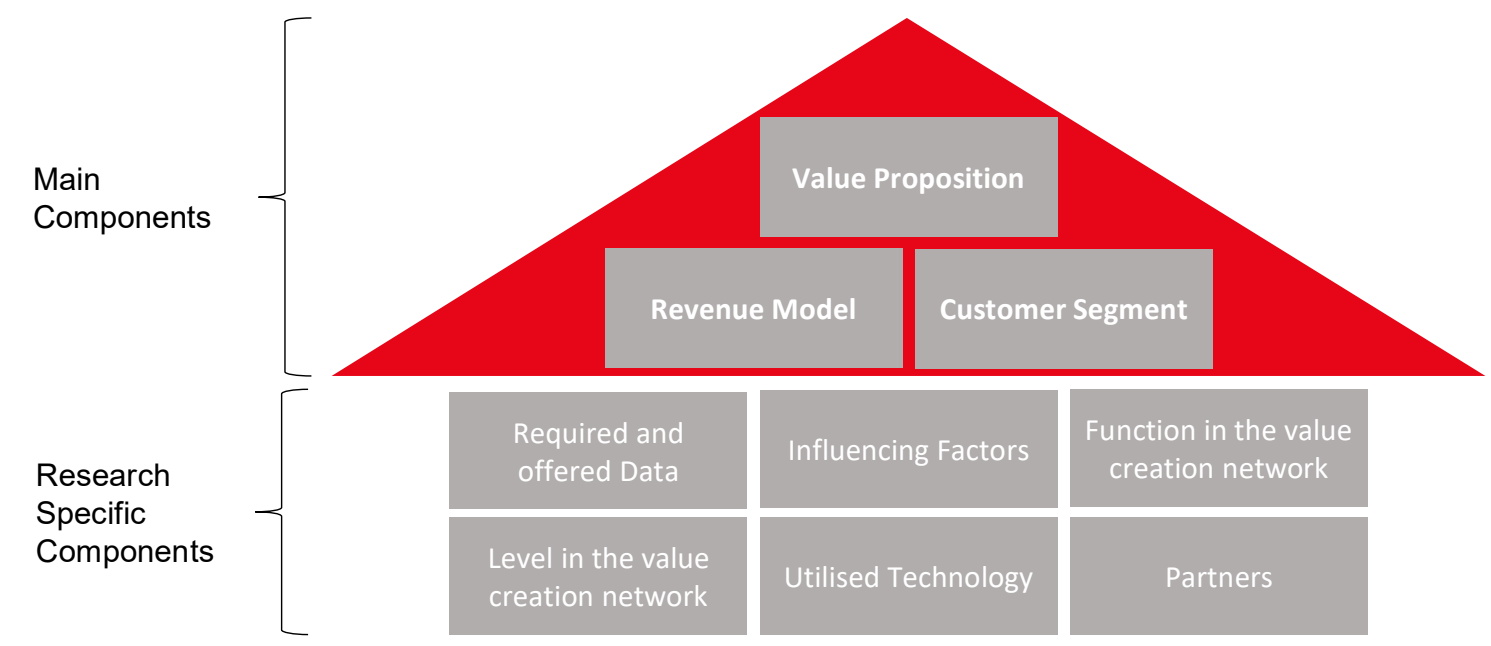

Figure 6. Overview of the components of the business model framework for the energy transformation (BMFE).

According to this logic, the main components within a business model prototype are identical. Consequently, all business models with identical main components are typified into one prototype. 


\subsubsection{Classification of Business Model Prototypes}

Following the typification for prototyping, the classification requires a further abstraction. The starting point is grouping the prototypes based on their position in the value creation network. The dimensions of consumer proximity and core activities of the energy industry are used for the classification of the prototypes. Double allocation of one prototype to two or more classes is not permitted. The classification takes the disruptive character of the energy system transformation into account by forming explicit individual classes based on decarbonisation, digitisation and decentralisation.

The splitting of the two dimensions of consumer proximity and core processes of the energy industry into traditional business models and modern business models shows the changing structure of the sector.

Figure 7 represents the basic categorisation of classes in the value creation network. Figure 8 illustrates an overview of the classes within the value creation network.

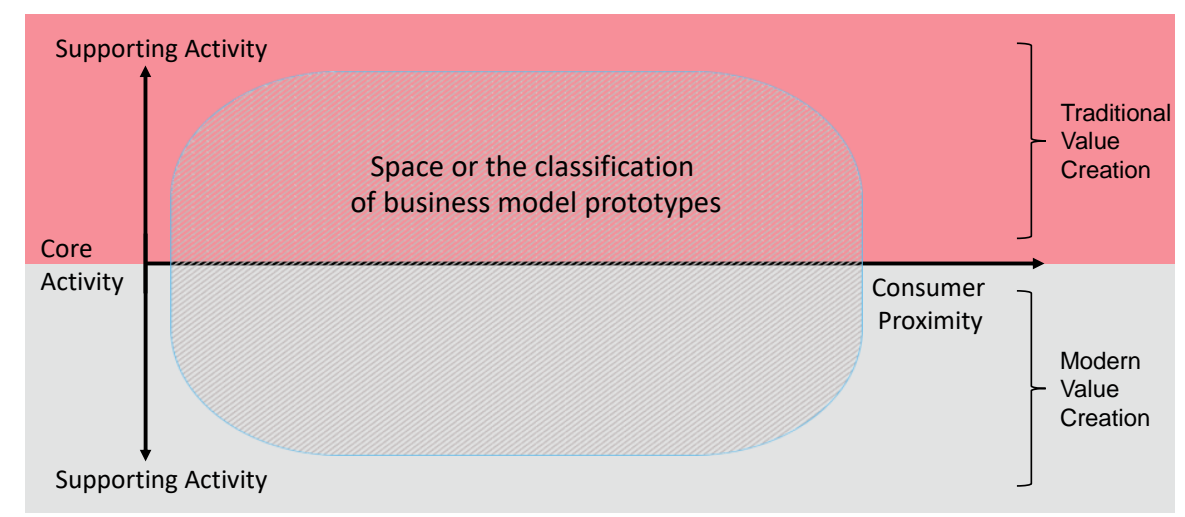

Figure 7. Dimensions for classifying the business models.

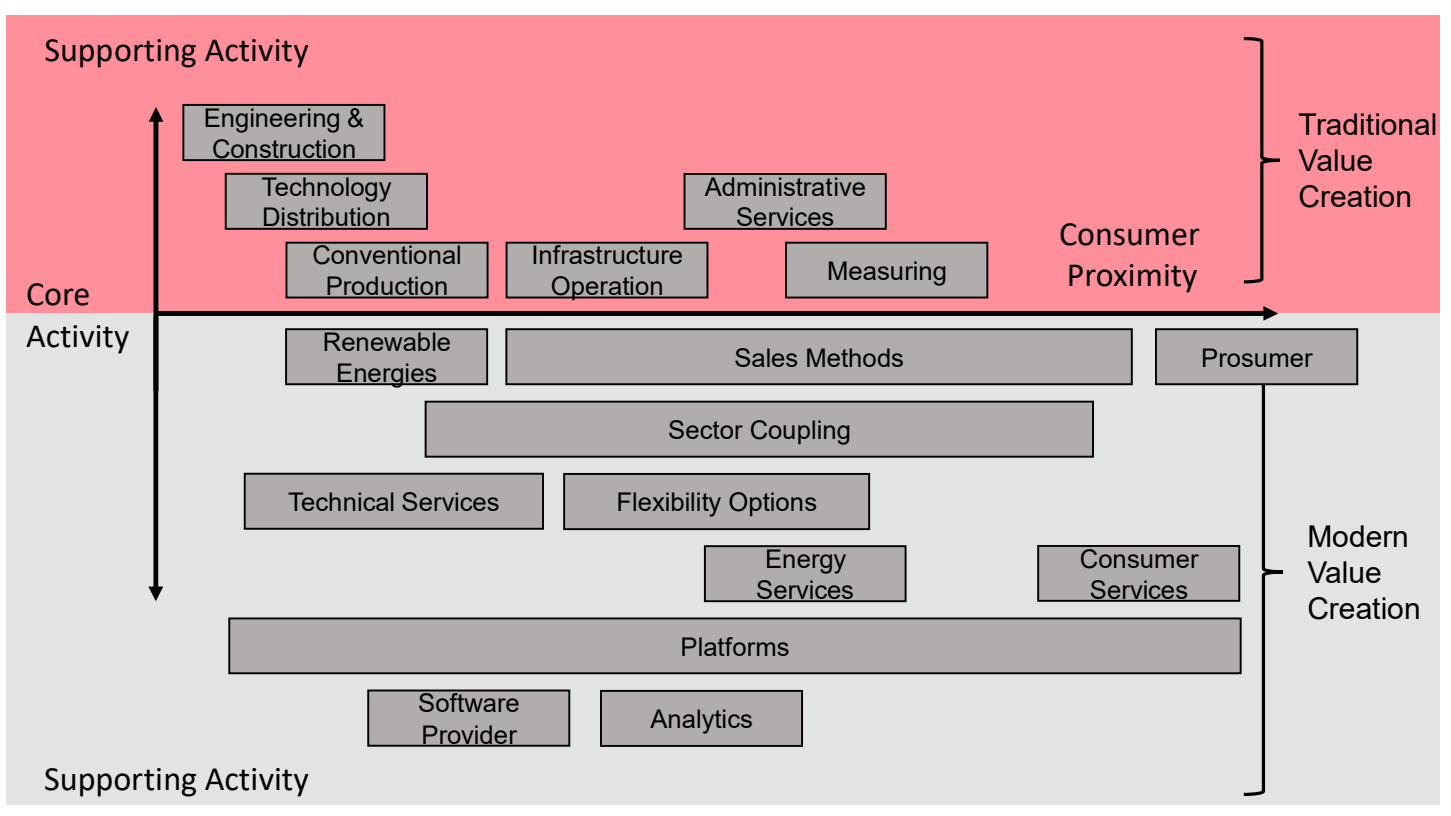

Figure 8. Overview of the business model classes.

In the long run, some classes (as well as prototypes and business models) might no longer exist, while further classes (as well as prototypes and business models) emerge. This is the outcome of economic development. Consequently, the prototypes and classification represent a snapshot of the current energy sector. 


\subsection{Extension of the Value Chain Approach to Value Networks}

The dynamic development caused by decarbonisation, decentralisation and digitalisation in the energy system is changing the traditional energy industry. Additionally, the emergence of new market roles and market players from outside the sector accelerates this change process. This results in new, complex and multi-layered interdependencies of actors challenging the classical value chain approach. The focus on single relationships between the business models themselves becomes less relevant. A more accurate analysis system is a value creation network. Value creation networks illustrate the interrelationships between the business model classes or business model prototypes. This aspect is represented by the dimension 'proximity to the classical value chain' in the classification of business models.

Porter (2004) created the principles of this approach with his introduction of the value system [35]. However, this approach goes one step further by including not only interdependencies along the steps of the classic value chain. The value creation network approach also includes a large number of cross-sectional functions as well as related supporting value creation areas and industries. The latter aspect is not represented in the classic value chain. Thus, the representation of a multitude of interactions represents a significant extension of Porter's approach.

The development of a value creation network is an instrument for the visualisation and analysis of the corresponding interactions. In a first step, the analysis of value networks at the prototype level is limited to those business model prototypes directly connected to the analysed business model prototype. Prototypes involved indirectly via several prototypes are not mapped. Analytically, this includes the representation of the respective product, service, energy, data, and financial flows between the market players.

\section{Current Business Models, Business Model Prototypes and Classes}

In accordance with the focus on the impact of decarbonisation, decentralisation and digitisation, the analysis shows that innovative business models are evident in addition to traditional ones. For example, one outcome of the increasing importance of digitisation are various business models linked to energy services, renewable energies, or sector coupling.

The comparison of the two analytical strands shows that the practical and the theory-based search support each other. Consequently, both analyses lead to similar business models. Some business models are identified more often via one or the other analysis approach.

\subsection{Results of the Practice-Based Analysis}

The practice-based analysis of the energy sector covers 134 companies. Due to the regional focus 218 of the business models were found at German companies while 16 were part of German incubators or foreign subsidiary companies. The number of 242 business models results from applying the methodology by Yin (2013) for cases with embedded investigation units [29]. Large utilities and public utilities contribute to $50 \%$, associations and statements to $20 \%$ and Start-Ups to $26 \%$ of the business models. A total of $4 \%$ of the business models of the practice-based analysis cannot be assigned to one of the three sources.

As expected, (integrated) utilities and municipal utilities cover many business models in the field of traditional business models. However, their contribution to more innovative business models is low. In the case of recent technology developments, the business model description is less precise. The imprecise description is due to the fact that novel business models are not yet fully developed and applied in the market. This aspect particularly concerns newer business models of software providers and analytics.

In terms of sector coupling, power-to-mobility concepts are predominant in practice. The mobilityrelated business models are more precisely described than other sector coupling concepts because they are more established on the market. In contrast, business models for smart homes are more fragmented 
and limited to selected individual technologies. Rarely are all aspects of a comprehensive building solution available. Start-ups usually concentrate on one technology option. Similarly, new entrants from other industries only enter the sector where they have the appropriate skills. Nevertheless, several companies are part of the necessary value creation network for a specific customer solution.

\subsection{Results of the Theory-Based Analysis}

The literature analysis covers 166 thematically matching publications. A total of 396 theory-based business models result from this analysis strand. Due to the research focus, the majority of the publications included in the business model analysis refer to the German or European market. Furthermore, one-fifth of the business model descriptions in literature were general and without reference to a region. These business model descriptions were also considered in the following typification and classification.

Traditional business models for generation, transport, distribution, and sales of energy dominate the theory-based analysis. The influence of decarbonisation on the value creation of the electricity sector is evident from numerous business models for renewable energies. Comparison to the practice-based analysis, the theoretical business models are more holistic. Cross-sectoral concepts require holistic solutions. Therefore, sector coupling business models such as power-to-gas, power-to-heat and smart grid concepts are predominantly found in the theory-based analysis. Compared to the practice-based analysis, the prosumer is explicitly mentioned and listed as an essential part of the energy industry's value creation network.

\subsection{Classification of Business Models}

The theory and practice-based analysis results in 69 prototypical business models. The classification of these prototypes results in the 17 business model classes illustrated in Figure 8. A detailed list with all business modell prototypes and classes can be found in the Appendix B and in the supplementary material Text S1. The business models and classes cover the traditional, liberalised, decarbonised and digitised energy industry.

A selection of examples demonstrates that the complete coverage of diverse business models. At the same time, the selected prototypes ensure sufficient heterogeneity between different prototypes. The 17 business model classes illustrate the development of the energy industry in recent years. The trends decarbonisation, liberalisation, decentralisation and digitisation give rise to new classes of business models alongside the traditional sector.

The business models in the class 'Infrastructure Operation' are examples of the traditional energy industry:

- 'Conventional Energy Supplier'

- 'Network Operator'

The liberalisation process led to the independent class 'Metering', including the prototypes:

- 'Metering Operator'

- 'Smart Meter Services'

Decarbonisation triggered the establishment of business models in the class 'Renewable energies':

- 'Renewable Fuels'

- 'Renewable Generation'

- 'Renewable Energy Supplier'

The necessary accuracy of differentiation between business model prototypes exits. The accuracy is exemplary noticeable by the two business model prototypes 'Renewable Generation' and 'Renewable Energy Supplier. Both offer the same value proposition with renewable electricity or heat. However, due to the different customer groups addressed and the technologies used, there are two differentiated 
business model prototypes. Nevertheless, due to the proximity to each other, a company may offer both in an integrated way.

The class 'platforms' extends the energy as a result of digitisation. The following prototypes represent the class:

- 'Crowd-Storage'

- 'Virtual Power Plant (VPP) Energy Marketing'

- 'Peer-to-Peer-Platform'

The class 'sector coupling' includes further new business models:

- 'Power-to-Gas'

- 'Power-to-Heat'

- 'Power-to-Mobility—Charging Infrastructure'

\subsection{Example of a Value Creation Network}

The individual business model prototypes are located within a value creation network. The business model description by the BMFE is used as an analytical tool to determine relations between business models. As an example, the value network for the business model prototype 'Virtual Power Plant Energy Marketing' is illustrated in Figure 9.

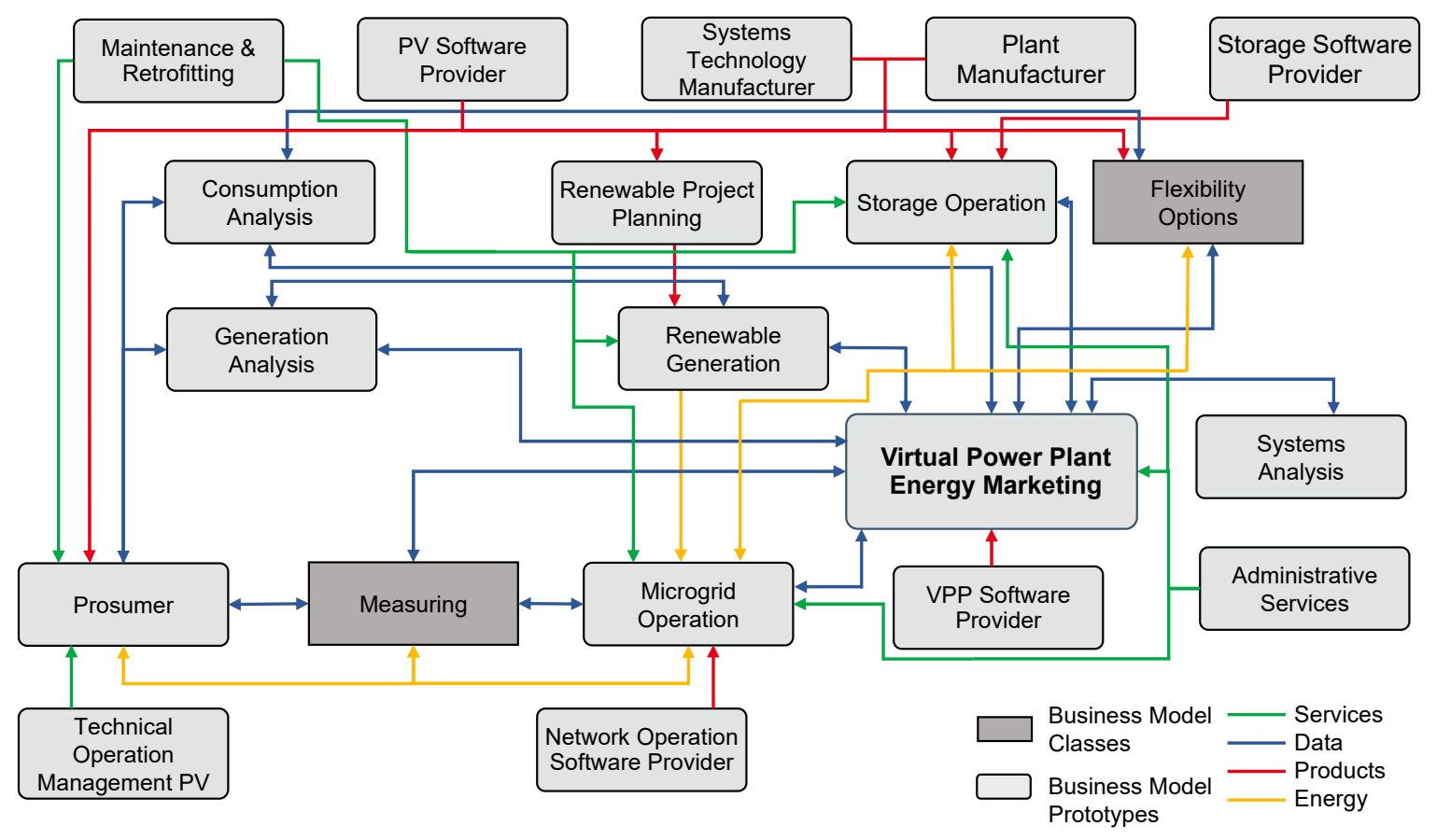

Figure 9. Value creation network of a virtual power plant (VPP).

The figure shows a map of services, data, products and energy flows of the business model prototype 'Virtual Power Plant Energy Marketing'. Payment flows are opposite to the services and products and not depicted (Exceptions are possible, for example within the framework of mandatory notification obligations, which can result by information flows without a financing stream). The result illustrates the multitude and variety of customers, suppliers and partners that a Virtual Power Plant requires. It also shows that a Virtual Power Plant only transports data. Concerning the electricity flow, the Virtual Power Plant is neither directly involved in generation nor transport.

Such a network can be created for each of the business model prototypes and offers practical use. For example, on a regional basis, a value creation network maps already existing prototypical 
business models or existing companies and their business models and consequently identifies gaps in this network to be filled by the local economy.

Incentives can be established to fill these gaps in order to promote local value creation. For this purpose, the value creation network can identify gaps in the local business model landscape. Companies can use a value creation network for their business models or those of their customers to identify potential for diversification or disruption.

\section{Conclusions and Further Research}

The paper shows that previous business model designs are insufficient for capturing the current business models of the energy industry. Especially for further work, there is a need for continued monitoring of business models in the energy sector in order to continue developing the proposed modular design of the BMFE. Therefore, Section 5.1 summarises the results of the analysis, while Section 5.2 emphasises the resulting need for further research.

\subsection{Summary of the Analysis}

Based on the structure of the energy industry and the effects of the energy transformation on business models, the BMFE tool is developed to describe the business models of the energy industry. A primary (practice-based) and secondary (theory-based) data collection identifies a total of 638 business models. The results of both analysis approaches mutually confirm each other. In synthesis, 69 business model prototypes were extracted from the analysis strands and described by the BMFE. One prototype summarises various business models with a similar value proposition, revenue model and customer segments. The classification of the 69 prototypes results in 17 business model classes according to the dimensions of 'customer proximity' and 'proximity to the classic value chain of the energy industry'.

The synthesis represents the current status of energy business models, business model prototypes and business model classes with a focus on Germany. The ongoing energy system transformation and the growth of renewable energies are changing the structure and value creation of the energy industry. The business model classes show that traditional business models are affected by the decarbonisation, decentralisation and digitisation of the energy system in all segments and economic sectors. Consequently, the energy transformation is beginning to have an impact beyond the borders of the electricity sector. The increasingly decentralised use of technologies from the heat, gas and mobility sectors shows that the requirements for coordination between sectors are increasing. Therefore, one company can no longer master all complex value creation tasks. Moreover, new and more complex interdependencies are emerging between business models.

In an energy sector increasingly characterised by complex value creation networks, the integrated combination of material and services is gaining in relevance. In particular, existing business models with direct end customer contact are dependent on the integration of additional services in the long term. In this context, the analysis confirms that digitisation drives and enables the transformation of energy systems. Many new companies are entering the market with innovative products based on digital solutions. Companies from the information and communication sector and other companies from outside the industry increasingly drive the change. This is, in particular, valid for new services that go beyond the mere supply of energy. For example, software, automation and platform solutions or solutions for sector coupling with the related areas of mobility and heat are gaining importance. Here, new entrants from other sectors can provide essential skills for the provision of innovative value propositions by entering the energy sector. However, traditional companies in the energy industry can also expand their product portfolio based on their expertise within their value creation network.

\subsection{Further Research}

The result of the analysis represents the status quo of the business models and business model classes of the energy industry in Germany and Europe. Therefore, the overview is limited to this region. However, the mentioned trends have as well an impact in other regions of the world. 
However, the transferability needs further investigation. Furthermore, the energy sector is constantly changing. In this context, the identified business model prototypes must be reviewed in the future and, if necessary, complemented.

Another limitation results from the qualitative approach. While this project applies a methodical qualitative description of the value network approach, an extension of the analysis instrument by a quantitative evaluation of cash flows is possible. Economic indicators could confirm the relevance of the business models. Therefore, one starting point for further research is the development of a quantitative model-based evaluation system, which allows a quick decision on the microeconomic applicability of a business model (-prototype). The authors have already started working on this issue. Furthermore, it is possible to extend individual value creation networks into higher-level overall networks. Thus, indirect effects in the broader sector environment can be analysed.

In the empirical analysis, business model prototypes were analysed independently of the companies realising them. By identifying the market players and recording the regional scalability of a business model prototypes, it is possible to transfer the systematisation to small-scale study regions. This regional economic and business model analysis could be realised in further projects. Initial research work has also started recently at the chair of Energy and Resource Management at the Technische Universität Berlin.

Due to constant changes in the (energy) economy, it is necessary to consistently monitor business models in order to add further components to the modular BMFE, if empirical evidence shows that this is necessary. This aspect covers a possible extension or reduction of business model prototypes or classes if new developments result in new business models. Such an adaptation of the results of this analysis is quite feasible with the presented methodology.

Supplementary Materials: The following are available online at doi.org/10.5281/zenodo.3518997 or https://www. er.tu-berlin.de/menue/veroeffentlichungen: Text S1, Overview of the components of the business model framework for the energy transformation (BMFE).

Author Contributions: J.G. and H.G. both surveyed the data and developed the BMFE. Together with B.G., J.K. and J.M.-K., they developed the general methodology. The main parts are written, and visualisations created by J.G. and H.G. with the support of B.G. and J.K. B.G., J.K. and J.M.-K. initiated the research and managed the editing process. All authors have read and agreed to the published version of the manuscript.

Funding: This article was written within the Copernicus project "Systemintegration": EnergiewendeNavigationssystem (ENavi) (funding code 03SFK4N0) funded by the German Federal Ministry of Education and Research (BMBF). The authors would like to give thanks for the financing of the work.

Acknowledgments: Previous works of this research have been presented at the Enerday2019 in Dresden. We, therefore, thank the conference and workshop audiences as well as three anonymous reviewers for useful discussions and suggestions, the usual disclaimer applies. We also like to thank Friederike Dobler and Flora v. Mikulicz-Radecki for contributing to this paper in earlier stages.

Conflicts of Interest: The authors declare no conflict of interest. The funders had no role in the design of the study; in the collection, analyses, or interpretation of data; in the writing of the manuscript, or in the decision to publish the results.

\section{Appendix A}

Table A1. Keywords of the Secondary Data Collection (Literature Review).

\begin{tabular}{lll}
\hline Keyword & "Energiewende" & business model \\
\hline $\begin{array}{l}\text { Synonyms } \\
\text { of the keyword }\end{array}$ & $\begin{array}{l}\text { shift/ } \\
\text { energy system transformation }\end{array}$ & business design \\
\hline $\begin{array}{l}\text { Umbrella terms for } \\
\text { the keyword }\end{array}$ & $\begin{array}{l}\text { renewable energies, } \\
\text { digitisation, digitalisation } \\
\text { decentralization, } \\
\text { decarbonisation }\end{array}$ & $\begin{array}{l}\text { business model type, } \\
\text { business organization/-concept } \\
\text { business idea }\end{array}$ \\
\hline
\end{tabular}


Table A1. Cont.

\begin{tabular}{|c|c|c|}
\hline $\begin{array}{l}\text { Sub terms/ } \\
\text { more detailed } \\
\text { specification of the keyword }\end{array}$ & $\begin{array}{l}\text { digital transformation, } \\
\text { innovation, } \\
\text { disruption, } \\
\text { information technologies, } \\
\text { energy industry, } \\
\text { energy }\end{array}$ & $\begin{array}{l}\text { business model canvas, } \\
\text { value, } \\
\text { value creation, } \\
\text { value added creation }\end{array}$ \\
\hline Related terms of the keyword & $\begin{array}{l}\text { EEG } \\
\text { (Erneuerbare-Energien-Gesetz), } \\
\text { EnWG } \\
\text { (Energiewirtschaftsgesetz), } \\
\text { KWKG } \\
\text { (Kraft-Wärme-Kopplungsgesetz), (The EEG, EnWG } \\
\text { and KWKG are specific German energy laws) } \\
\text { green electricity, } \\
\text { grid expansion, } \\
\text { smart grids, smart meter, } \\
\text { 4. industrial revolution, } \\
\text { digital energy }\end{array}$ & $\begin{array}{l}\text { commercialization, } \\
\text { corporate/company networks, } \\
\text { revenue model, } \\
\text { value proposition }\end{array}$ \\
\hline
\end{tabular}

\section{Appendix B}

Table A2. Business Model Classes and included Prototypes.

\begin{tabular}{l}
\hline Business Model Classes \\
\hline Business model prototypes \\
\hline Platforms \\
\hline Stock Exchange \\
Crowd Storage Platform \\
Information Platform \\
Power-to-Mobility Charging Infrastructure Platform \\
Peer to Peer Platform \\
Platform for Energy Services \\
VPP Energy Marketing \\
VPP System Services \\
\hline Software Provider \\
\hline Energy Efficiency Software Provider \\
Network Operation Software Provider \\
Power-to-Mobility Software Provider \\
Platform Software Provider \\
PV Software Provider \\
Storage Software Provider \\
VPP Software Provider \\
\hline Sales Methods \\
\hline Consumer Sales \\
Energy Trading \\
Customer Services based on Energy Data \\
Storage Trade \\
System Services Marketing \\
Marketing \\
Distribution of related Goods \\
\hline Technical Services \\
\hline Carbon Capture and Storage (CCS) \\
Energy Management System \\
Renewable Project Planning \\
Power Plant \& Grid Project Planning \\
Modernisation \\
Maintenance \& Retrofitting \\
\hline
\end{tabular}


Table A2. Cont.

\begin{tabular}{|c|}
\hline Flexibility Options \\
\hline Demand Side Management (DSM) \\
\hline DSM system services \\
\hline Power-to-Mobility DSM \& System Services \\
\hline Storage DSM \\
\hline Storage System Services \\
\hline Analytics \\
\hline Data Trading \\
\hline Generation Analysis \\
\hline Systems Analysis \\
\hline Consumption Analysis \\
\hline Consumer Services \\
\hline Energy Consulting \\
\hline Mobility Services \\
\hline Procurement \\
\hline Testing Services \\
\hline Energy Services \\
\hline Energy Contracting \\
\hline Power for Tenants \\
\hline Technical Operations Management \\
\hline Technical Operations Management PV \\
\hline Infrastructure Operation \\
\hline Asset Leasing \\
\hline Microgrid Operation \\
\hline Network Operation \\
\hline Storage Operation \\
\hline Sector Coupling \\
\hline Power-to-Gas \\
\hline Power-to-Heat \\
\hline Power-to-Mobility Power Supply \\
\hline Power-to-Mobility Charging Infrastructure \\
\hline Administrative Services \\
\hline Billing Services \\
\hline Administrative Services \\
\hline Distribution Services \\
\hline Renewable Energies \\
\hline Renewable Fuels \\
\hline Renewable Generation \\
\hline Renewable Energy Supplier \\
\hline Measuring \\
\hline Measuring Services \\
\hline Metering Point Operator \\
\hline Smart Meter Services \\
\hline Engineering \& Construction \\
\hline Plant Manufacturer \\
\hline Systems Technology Manufacturer \\
\hline Technology Sales \\
\hline System Distribution \\
\hline Technology Distribution \\
\hline
\end{tabular}


Table A2. Cont.

\begin{tabular}{l}
\hline Conventional Production \\
\hline Conventional Production \\
Conventional Energy Supplier \\
\hline Prosumer \\
\hline Prosumer \\
\hline
\end{tabular}

\section{References}

1. Mühlemeier, S.; Wyss, R.; Binder, C.R. Und Aktion!-Konzeptualisierung der Rolle individuellen Akteurshandelns in sozio-technischen Transitionen am Beispiel der regionalen Energiewende im bayerischen Allgäu. Z. für Energiewirtsch. 2017, 41, 187-202. [CrossRef]

2. Quitzow, L.; Canzler, W.; Grundmann, P.; Leibenath, M.; Moss, T.; Rave, T. The German Energiewende-What's happening? Introducing the special issue. Util. Policy 2016, 41, 163-171. [CrossRef]

3. Shaffer, B.; Flores, R.; Samuelsen, S.; Anderson, M.; Mizzi, R.; Kuitunen, E. Urban energy systems and the transition to zero carbon-Research and case studies from the USA and Europe. Energy Procedia 2018, 149, 25-38. [CrossRef]

4. Varela, I. Smart Energy—Die Digitalisierung der Energiewirtschaft. In Marktplätze im Umbruch, 1st ed.; Linnhoff-Popien, C., Zaddach, M., Grahl, A., Eds.; Springer: Berlin/Heidelberg, Germany, 2015; pp. 495-502, ISBN 978-3-662-43781-0.

5. Löbbe, S.; Hackbarth, A. The Transformation of the German electricity sector and the emergence of new business models in distributed energy systems. In Innovation and Disruption at the Grid's Edge, 1st ed.; Sioshansi, F.P., Ed.; Academic Press: Cambridge, MA, USA, 2017; pp. 287-318, ISBN 978-0-12-811758-3.

6. Woodhouse, S.; Bradbury, S. Innovation, disruption, and the survival of the fittest. In Innovation and Disruption at the Grid's Edge, 1st ed.; Sioshansi, F.P., Ed.; Academic Press: Cambridge, MA, USA, 2017; pp. 25-39, ISBN 978-0-12-811758-3.

7. Bieger, T.; Knyphausen-Aufseß, D.z.; Krys, C. Innovative Geschäftsmodelle: Konzeptionelle Grundlagen, Gestaltungsfelder und unternehmerische Praxis, 1st ed.; Academic Network; Springer: Berlin/Heidelberg, Germany, 2011; ISBN 978-3-642-18067-5.

8. Drucker, P. The Practice of Management, 1st ed.; William Heinemann Ltd.: Portsmouth, NH, USA, 1955.

9. Demil, B.; Lecocq, X. Business Model Evolution: In Search of Dynamic Consistency. Long Range Plan. 2010, 43, 227-246. [CrossRef]

10. Osterwalder, A.; Pigneur, Y. Business Model Generation A Handbook for Visionaries, Game Changers, and Challengers, 1st ed.; John Wiley \& Sons: New York, NY, USA, 2013; ISBN 978-1-118-65640-2.

11. Teece, D.J. Business Models, Business Strategy and Innovation. Long Range Plann. 2010, 43, $172-194$. [CrossRef]

12. Provance, M.; Donnelly, R.G.; Carayannis, E.G. Institutional influences on business model choice by new ventures in the microgenerated energy industry. Energy Policy 2011, 39, 5630-5637. [CrossRef]

13. Doleski, O.D. Entwicklung neuer Geschäftsmodelle für die Energiewirtschaft-Das Integrierte Geschäftsmodell. In Smart Market, 1st ed.; Aichele, C., Doleski, O.D., Eds.; Springer Fachmedien Wiesbaden: Wiesbaden, Germany, 2014; pp. 643-703, ISBN 978-3-658-02777-3.

14. PWC. Deutschlands Energieversorger Werden Digital; PricewaterhouseCoopers Aktiengesellschaft Wirtschaftsprüfungsgesellschaft: Frankfurt, Germany, 2016.

15. Varone, A.; Ferrari, M. Power to liquid and power to gas: An option for the German Energiewende. Renew. Sustain. Energy Rev. 2015, 45, 207-218. [CrossRef]

16. Burger, S.P.; Luke, M. Business models for distributed energy resources: A review and empirical analysis. Energy Policy 2017, 109, 230-248. [CrossRef]

17. Löbbe, S.; Hackbarth, A. Geschäftsmodelle in der Energiewirtschaft: Ein Kompendium von der Methodik bis zur Anwendung; Reutlinger Diskussionsbeiträge zu Marketing \& Management; Hochschule Reutlingen: Reutlingen, Germany, 2017.

18. Richter, M. Utilities' business models for renewable energy: A review. Renew. Sustain. Energy Rev. 2012, 16, 2483-2493. [CrossRef] 
19. Loock, M. Going beyond best technology and lowest price: On renewable energy investors' preference for service-driven business models. Energy Policy 2012, 40, 21-27. [CrossRef]

20. Strupeit, L.; Palm, A. Overcoming barriers to renewable energy diffusion: Business models for customer-sited solar photovoltaics in Japan, Germany and the United States. J. Clean. Prod. 2016, 123, 124-136. [CrossRef]

21. Okkonen, L.; Suhonen, N. Business models of heat entrepreneurship in Finland. Energy Policy 2010, 38, 3443-3452. [CrossRef]

22. Jahnke, P.; Monjau, R.; Dziomba, H. Geschäftsmodellansätze für Mini-/Mikro-KWK und intelligente Infrastrukturen. In Lokale Impulse für Energieinnovationen, 1st ed.; Fuchs, G., Ed.; Springer Fachmedien Wiesbaden: Wiesbaden, Germany, 2017; pp. 161-204, ISBN 978-3-658-14800-3.

23. Rodríguez-Molina, J.; Martínez-Núez, M.; Martínez, J.-F.; Pérez-Aguiar, W. Business Models in the Smart Grid: Challenges, Opportunities and Proposals for Prosumer Profitability. Energies 2014, 7, 6142-6171. [CrossRef]

24. Giordano, V.; Fulli, G. A business case for Smart Grid technologies: A systemic perspective. Energy Policy 2011. [CrossRef]

25. EY Geschäftsmodelle 2020-Wie in der Energiewirtschaft zukünftig Noch Geld Verdient Werden Kann; Ernst \& Young GmbH Wirtschaftsprüfungsgesellschaft: Stuttgart, Germany, 2016.

26. Abdelkafi, N.; Makhotin, S.; Posselt, T. Business model innovations for electric mobility—What can be learned from existing business model patterns? Int. J. Innov. Manag. 2013, 17, 1340003-1-1340003-41. [CrossRef]

27. Kasperk, G.; Drauz, R. Geschäftsmodelle entlang der elektromobilen Wertschöpfungskette. In Elektromobilität, 1st ed.; Kampker, A., Vallée, D., Schnettler, A., Eds.; Springerg: Berlin/Heidelberg, Germany, 2013; pp. 103-148, ISBN 978-3-642-31985-3.

28. Gioia, D.A.; Corley, K.G.; Hamilton, A.L. Seeking Qualitative Rigor in Inductive Research: Notes on the Gioia Methodology. Organ. Res. Methods 2013, 16, 15-31. [CrossRef]

29. Yin, R.K. Case Study Research: Design and Methods, 5th ed.; Sage Publications: Thousand Oaks, CA, USA, 2013; ISBN 978-1-4833-2224-7.

30. Flick, U. Triangulation. In Empirische Forschung und Soziale Arbeit, 1st ed.; Oelerich, G., Otto, H.-U., Eds.; VS Verlag für Sozialwissenschaften: Wiesbaden, Germany, 2011; pp. 323-328, ISBN 978-3-531-17204-0.

31. BMWi LEISTUNGSBESCHREIBUNG zum Dienstleistungsvorhaben. Die Energiewirtschaft im Rahmen der Energiewende: Wissenschaftliche Analysen zu wirtschaftlichen Fragen und Zukunftsperspektiven der Energiewirtschaft (Kurztitel EVU Strukturwandel); Tender Documents; Bundesministerium für Wirtschaft und Energie: Berlin, Germany, 2017.

32. BMWi Stellungnahmen-Konsultationen zu Aktuellen Gesetzesvorhaben. Available online: http://www. erneuerbare-energien.de/EE/Navigation/DE/Service/Stellungnahmen/stellungnahmen.html (accessed on 13 November 2017).

33. Kitchenham, B.; Brereton, P. A systematic review of systematic review process research in software engineering. Inform. Softw. Technol. 2013, 55, 2049-2075. [CrossRef]

34. Backhaus, K.; Erichson, B.; Plinke, W.; Weiber, R. Multivariate Analysemethoden: Eine Anwendungsorientierte Einführung, 14th ed.; Springer Gabler: Berlin/Heidelberg, Germany, 2016; ISBN 978-3-662-46076-4.

35. Porter, M.E. Competitive Advantage: Creating and Sustaining Superior Performance, 1st ed.; Free Press Export, Ed.; Free Press: New York, NY, USA, 2004; ISBN 978-0-7432-6087-9.

(C) 2020 by the authors. Licensee MDPI, Basel, Switzerland. This article is an open access article distributed under the terms and conditions of the Creative Commons Attribution (CC BY) license (http://creativecommons.org/licenses/by/4.0/). 